\title{
A rise in mean platelet volume during hospitalization for community-acquired pneumonia predicts poor prognosis: a retrospective observational cohort study
}

Oleg Gorelik ${ }^{1,3^{*}}$ D, Irma Tzur ${ }^{1,3}$, Dana Barchel ${ }^{1,3}$, Dorit Almoznino-Sarafian ${ }^{1,3}$, Muhareb Swarka ${ }^{1,3}$, Ilia Beberashvili ${ }^{2,3}$, Leonid Feldman ${ }^{2,3}$, Natan Cohen ${ }^{1,3}$ and Shimon Izhakian ${ }^{1,3}$

\begin{abstract}
Background: Clinical characteristics and the prognostic significance of changes in mean platelet volume (MPV) during hospitalization for community-acquired pneumonia (CAP) have not been investigated.

Methods: Among 976 adults hospitalized for CAP, clinical characteristics, in-hospital outcomes (transfer to the intensive care unit, treatment with mechanical ventilation, prolonged hospital stay and death), and all-cause mortality following discharge, were compared according to $\triangle M P V$ (MPV on discharge minus MPV on admission): groups A (no rising MPV, $\triangle \mathrm{MPV}<0.6 \mathrm{fL}$ ) and $\mathrm{B}$ (rising MPV, $\triangle \mathrm{MPV} \geq 0.6 \mathrm{fL}$ ).

Results: Groups A and B comprised $83.8 \%$ and $16.2 \%$ of patients, respectively. Patients with a rise in MPV were more likely to be older, and to present with renal dysfunction, cerebrovascular disorder and severe pneumonia than were patients with no rise in MPV. On discharge, lower values of platelets and higher levels of neutrophils were observed in group B. Rising MPV strongly predicted a need for mechanical ventilation and in-hospital death (the respective relative risks: 2.62 and 6.79; 95\% confidence intervals: 1.54-4.45 and 3.48-13.20). The respective 90-day, 3-year and total (median follow-up of 54 months) mortality rates were significantly higher in group B $(29.1 \%, 43.0 \%$ and 50 . $0 \%$ ) than group A (7.3\%, 24.2\% and 32.6\%), $p<0.001$ for all comparisons. A rise in MPV was a powerful predictor of allcause mortality (relative risk 1.26 and 95\% confidence interval 1.11-1.43).
\end{abstract}

Conclusions: Rising MPV during hospitalization for CAP is associated with a more severe clinical profile than no rise in MPV. A rise in MPV strongly predicts in-hospital and long-term mortality.

Keywords: Mean platelet volume, Community-acquired pneumonia, Hospitalization, Prognosis

\section{Background}

Platelets play an important role in processes of hemostasis, inflammation and immunity $[1,2]$. Mean platelet volume (MPV) is a routine laboratory test that is measured in complete blood count and considered a marker of platelet function and activation [3, 4]. A single measurement of elevated MPV has been reported to be associated with increased morbidity and mortality in

\footnotetext{
* Correspondence: internal6@asaf.health.gov.il; pg15@zahav.net.il 'Department of Internal Medicine "F", Assaf Harofeh Medical Center, 70300 Zerifin, Israel

${ }^{3}$ Sackler Faculty of Medicine, Tel Aviv University, Ramat Aviv, Tel Aviv, Israel

Full list of author information is available at the end of the article
}

various patient populations [3-7]. Moreover, MPV is a dynamic parameter that may change significantly within several days or weeks [8-15]. In a number of studies consisting of patients with critical illness [8,11, 12, 14], bacteremia [10], coronary artery disease $[9,15]$ and heterogeneous disorders [13], a rise in MPV over time was identified as a powerful predictor of morbidity and mortality.

Patients hospitalized with community-acquired pneumonia (CAP) are at an increased risk of death in the hospital and following discharge [16-18]. The prognostic significance of MPV has been reported in only two small studies on CAP patients, which were based on single 
MPV determinations $[19,20]$. The clinical characteristics and prognosis of time-dependent MPV changes have not been investigated in the CAP population. Therefore, we aimed to compare demographic, clinical, laboratory and radiographic characteristics, as well as short- and longterm outcomes of patients hospitalized for CAP, according to changes in MPV.

\section{Methods}

\section{Study population and design}

The study population comprised adult patients hospitalized for CAP during 2009-2012 in 7 internal medicine departments in our tertiary care university hospital. The availability of complete blood count at admission and within $48 \mathrm{~h}$ of discharge or death, and with intervals between the determinations of at least 3 days, was a study inclusion criterion. Patients transferred from another hospital or from an intensive care unit (ICU), with possible health care-associated and nosocomial pneumonia, primary hematological disorders, advanced malignant disease or platelet transfusion were excluded from the analysis. MPV and other blood count parameters were measured by an automated analyzer (Coulter ${ }^{\circ}$ A84148-AB; Beckman Coulter, Inc., CA, USA) with LH 750 control system. All blood samples were collected, handled and processed in the same way: venous blood was drawn into a test tube containing an anticoagulant (EDTA) and the samples were tested within $60 \mathrm{~min}$ of collection. In our laboratory, the range of normal MPV values is $7.3-11.5 \mathrm{fL}$, and the respective intra- and interassay coefficients of variability for MPV measurements are $\leq 2.2 \%$ and $\leq 6.3 \%$.

For analysis of time-dependent MPV changes, patients were categorized according to $\triangle \mathrm{MPV}$ (MPV on discharge minus MPV on admission) into: groups A (no rising MPV, $\triangle \mathrm{MPV}<0.6 \mathrm{fL}$ ) and $\mathrm{B}$ (rising MPV, $\triangle \mathrm{MPV} \geq 0.6 \mathrm{fL}$ ). Data were also compared between groups classified according to values of $\mathrm{MPV} \leq 8.5 \mathrm{fL}$ and $>8.5 \mathrm{fL}$ on admission (groups $1 \mathrm{adm}$ and $2 \mathrm{adm}$, respectively) and discharge (groups 1dis and 2dis, respectively). The study was carried out in accordance with the Declaration of Helsinki and was approved by the institutional Ethics Committee of the Assaf Harofeh Medical Center (approval number 019516-ASF).

\section{Data collection}

Demographic, clinical, radiographic and laboratory data were obtained retrospectively from the electronic medical records of the patients. We recorded the following outcomes during the current hospitalization: transfer to ICUs, treatment with mechanical ventilation, length of hospital stay and death. Death of any cause was registered at 90 days and 3 years following the current admission, and at the end of the follow-up period. Information about death was obtained from the registry of the Internal Affairs Ministry or from hospital records.

\section{Definitions}

A $\triangle \mathrm{MPV} \geq 0.6 \mathrm{fL}$ was chosen to minimize the chance of misclassification of patients due to known normal individual variability or measured counter variability of MPV [4], and according to findings in other relevant investigations [14]. The rationale to use the cutoff of $8.5 \mathrm{fL}$ for MPV values on admission and discharge was based on a previous report in which this threshold was optimal for predicting mortality in CAP patients [20]. Anemia was defined using the World Health Organization criteria: a hemoglobin concentration of $<13 \mathrm{~g} / \mathrm{dl}$ in men and $<12 \mathrm{~g} / \mathrm{dl}$ in women. Renal dysfunction was diagnosed according to any value of estimated glomerular filtration rate $<60 \mathrm{ml} / \mathrm{min} / 1.73 \mathrm{~m}^{2}$ during current hospitalization, using the Modification of Diet in Renal Disease equation [21].

CAP was diagnosed according to the following criteria: the presence of acute illness with symptoms and signs of lower respiratory tract infection and a new chest radiographic infiltrate; no evidence of another clear diagnosis or of acquirement in a hospital or of being associated with health care [16-18]. Patients were stratified into risk classes according to the Pneumonia Severity Index (PSI) and CURB-65 scores calculated at hospital admission [22, 23].

\section{Statistical analysis}

The statistical analysis was performed using the Biomedical Package (BMDP) software program [24]. The results were expressed as means and standard deviations for quantitative data, and as percentages for qualitative data. Statistical comparisons were performed for groups A vs. B, 1adm vs. 2adm, and 1dis vs. 2 dis. Categorical variables were compared using Pearson's chi-square or Fisher's exact test. Analysis of Variance (ANOVA) was applied for continuous variables. Survival estimates were provided using the KaplanMeier method. Mantel-Cox and Breslow tests were applied to evaluate differences between the curves. $P$ values $\leq 0.05$ were considered statistically significant. Variables that most significantly predicted poor inhospital outcomes were evaluated by stepwise logistic regression with determination of the area under the curve (AUC) of the receiver operating characteristic plots. Variables that were found to be associated with shortened survival using the Kaplan-Meier method were reevaluated by the Cox proportional-hazards model to identify those most significantly associated with mortality. 


\section{Results}

Characteristics of the patients

Entire sample

Data for the 976 patients who were included in the study are presented in Table 1. Groups A (no rising MPV) and $\mathrm{B}$ (rising MPV) comprised $83.8 \%$ and $16.2 \%$ of the patients, respectively. MPV values > $8.5 \mathrm{fL}$ on admission and discharge were found among $48.3 \%$ and $43.0 \%$ of patients, respectively.

\section{Comparisons according to MPV changes (group A vs. $B$, Table 1)}

Patients with a rise in MPV were more likely to be older, and to present with renal dysfunction and cerebrovascular disorder than patients with no rise in MPV. Mean values of CURB-65 and PSI scores were significantly higher in group B (rising MPV). Moreover, on discharge, lower values of platelets, as well as higher levels of leukocytes and neutrophils were observed in group B.

\section{In-hospital outcomes}

Comparisons according to MPV changes (group A vs. B)

Patients with a rise in MPV were more likely to be treated with mechanical ventilation and to die during the current hospitalization than were patients with no rise in MPV (Table 1). On multivariate analysis, a rise in MPV was one of the variables that strongly predicted treatment with mechanical ventilation and in-hospital death (Table 2).

\section{Comparisons according to MPV at admission (group 1adm} vs. 2adm) and discharge (group 1dis vs. 2dis)

Patients in group 2adm were more often mechanically ventilated than were those in group $1 \mathrm{adm}(12.1 \%$ vs. $6.5 \%, p=0.003)$. Treatment with mechanical ventilation (13.8\% vs. $5.8 \%, p<0.001)$ and in-hospital death $(10.0 \%$ vs. $3.4 \%, p<0.001)$ were more likely observed in patients from group 2dis than in those from group 1dis. No statistically significant differences in any other inhospital outcomes were found between the groups (data are not presented). On multivariate analysis, none of the in-hospital outcomes were associated with MPV on admission or discharge.

\section{Survival}

\section{Entire sample}

The follow-up period extended up to 85 months (median 54 months). The respective 90-day, 3-year and total mortality rates for the entire sample were $11.2 \%, 27.6 \%$ and $35.5 \%$.

\section{Survival according to MPV changes (group A vs. B)}

Rising compared to not rising MPV was associated with increased all-cause mortality $(p<0.001$, Fig. 1a). The respective 90-day, 3-year and total mortality rates were significantly higher in group B $(29.1 \%, 43.0 \%$ and $50.0 \%)$ than in group A (7.3\%, 24.2\% and 32.6\%), $p<0.001$ for all comparisons.

\section{Survival according to MPV at admission (group 1adm vs. 2adm)}

No significant difference in survival was found between groups $1 \mathrm{adm}$ and $2 \mathrm{adm}$ : the respective 90-day, 3-year and total mortality rates were $11.5 \%, 27.3 \%$ and $36.8 \%$ vs. $10.2 \%, 27.2 \%$ and $34.0 \%$ ( $p>0.5$ for all comparisons).

\section{Survival according to MPV at discharge (group 1dis vs. 2dis)}

Mortality was higher among patients from group 2dis than among those from group 1 dis $(p=0.01$, Fig. 1b): the respective rates were $15.0 \%$ vs. $7.7 \%$ at 90 days $(p<0.001), 31.4 \%$ vs. $24.1 \%$ at 3 years $(p=0.01)$ and $39.0 \%$ vs. $32.7 \%$ at the end of follow-up $(p=0.01)$.

\section{The variables most significantly associated with decreased survival in the entire sample}

Univariate analysis revealed that advanced age, male sex, rise in MPV, MPV > 8.5 fL at discharge, anemia, renal dysfunction, diabetes mellitus, coronary artery disease, chronic lung disease, heart failure, cerebrovascular disease, history of malignancy, hyponatremia, hypoalbuminemia, and higher CURB-65 and PSI scores were associated with increased long-term mortality. Reevaluation of these variables by the Cox proportional-hazards model, separately for PSI and CURB-65 scores, showed that a rise in MPV was a powerful predictor of shortened survival in both models (the respective relative risks: 1.26 and 1.23, Table 3). However, elevated MPV at discharge did not remain significantly associated with mortality.

\section{Discussion}

The present investigation is the first report of clinical characteristics and prognosis associated with MPV changes during hospitalization for CAP. The main novelty of our study is the demonstration that a rise in MPV strongly predicts in-hospital and long-term mortality.

Information about prognostic significance of MPV among CAP patients is limited $[19,20]$. In one study comprising 196 children with CAP, baseline MPV values were significantly higher in hospitalized patients than in outpatients [19]. In another investigation of 174 adults presenting with CAP to an emergency department, MPV values below a cut-off of $8.55 \mathrm{fL}$, in combination with a CURB-65 score, strongly predicted 28-day all-cause mortality [20]. Compared to the aforementioned studies, the current 
Table 1 Characteristics of the patients analyzed in the study

\begin{tabular}{|c|c|c|c|c|}
\hline Characteristics & $\begin{array}{l}\text { Entire sample } \\
(n=976)\end{array}$ & $\begin{array}{l}\text { Group A No rising MPV } \\
\Delta \mathrm{MPV}<0.6 \mathrm{fL}(n=818)\end{array}$ & $\begin{array}{l}\text { Group B Rising MPV } \triangle \mathrm{MPV} \\
\geq 0.6 \mathrm{fL}(n=158)\end{array}$ & $\begin{array}{l}\text { Difference between groups } \\
\mathrm{A} \text { and } \mathrm{B} p \text {-value }\end{array}$ \\
\hline Age (years) & $64.6 \pm 21$ & $63.4 \pm 20$ & $70.7 \pm 21$ & $<0.001$ \\
\hline Male sex & $52.3 \%$ & $51.2 \%$ & $57.6 \%$ & 0.1 \\
\hline \multicolumn{5}{|l|}{ Comorbid conditions } \\
\hline Renal dysfunction & $33.6 \%$ & $31.3 \%$ & $45.6 \%$ & $<0.001$ \\
\hline Diabetes mellitus & $30.9 \%$ & $31.4 \%$ & $28.5 \%$ & 0.5 \\
\hline Coronary artery disease & $24.2 \%$ & $23.5 \%$ & $27.8 \%$ & 0.2 \\
\hline Chronic lung disease & $28.1 \%$ & $27.0 \%$ & $33.5 \%$ & 0.1 \\
\hline Heart failure & $16.8 \%$ & $15.8 \%$ & $22.2 \%$ & 0.06 \\
\hline Cerebrovascular disease & $16.9 \%$ & $15.2 \%$ & $25.9 \%$ & 0.001 \\
\hline History of malignancy & $8.4 \%$ & $8.2 \%$ & $9.5 \%$ & 0.6 \\
\hline $\begin{array}{l}\text { Acute bleeding during } \\
\text { hospitalization/blood transfusion }\end{array}$ & $3.3 \% / 6.0 \%$ & $2.9 \% / 5.7 \%$ & $5.1 \% / 7.6 \%$ & $0.5 / 0.4$ \\
\hline $\begin{array}{l}\text { Pleural effusion/bilateral lung } \\
\text { involvement }\end{array}$ & $25.8 \% / 16.0 \%$ & $25.8 \% / 15.5 \%$ & $25.9 \% / 18.4 \%$ & $1.0 / 0.4$ \\
\hline CURB-65 class & $1.78 \pm 1.0$ & $1.71 \pm 1.0$ & $2.15 \pm 1.1$ & $<0.001$ \\
\hline $\begin{array}{l}\text { Pneumonia Severity Index } \\
\text { score/risk class }\end{array}$ & $100.1 \pm 45 / 3.44 \pm 1.4$ & $98.3 \pm 44 / 3.36 \pm 1.4$ & $117.2 \pm 47 / 3.85 \pm 1.3$ & $<0.001 /<0.001$ \\
\hline \multicolumn{5}{|l|}{ Antibiotic treatment } \\
\hline Beta-lactam & $93.0 \%$ & $93.0 \%$ & $93.0 \%$ & 1.0 \\
\hline Macrolide & $62.4 \%$ & $61.5 \%$ & $67.1 \%$ & 0.2 \\
\hline Fluoroquinolone & $23.4 \%$ & $23.5 \%$ & $22.8 \%$ & 0.9 \\
\hline Other & $11.8 \%$ & $11.7 \%$ & $12.0 \%$ & 0.9 \\
\hline \multicolumn{5}{|l|}{ Laboratory data } \\
\hline $\begin{array}{l}\text { Hypoalbuminemia on admission } \\
(<34 \mathrm{~g} / \mathrm{l})\end{array}$ & $36.2 \%$ & $34.8 \%$ & $39.9 \%$ & 0.2 \\
\hline $\begin{array}{l}\text { Hyponatremia on admission } \\
(<135 \mathrm{mmol} / \mathrm{l})\end{array}$ & $37.9 \%$ & $39.1 \%$ & $31.0 \%$ & 0.06 \\
\hline $\begin{array}{l}\text { Hemoglobin on admission/ } \\
\text { discharge (normal 13.0-16.2 g/dl) }\end{array}$ & $12.5 \pm 2 / 12.0 \pm 2$ & $12.5 \pm 2 / 12.0 \pm 2$ & $12.4 \pm 2 / 11.7 \pm 2$ & $0.4 / 0.02$ \\
\hline Anemia on admission/discharge & $45.4 \% / 61.4 \%$ & $44.6 \% / 60.5 \%$ & $49.4 \% / 65.8 \%$ & $0.3 / 0.2$ \\
\hline $\begin{array}{l}\text { WBC count on admission/ } \\
\left.\text { discharge (normal } 4-11 \times 10^{9} / \mathrm{l}\right)\end{array}$ & $12.5 \pm 6 / 9.1 \pm 4$ & $12.6 \pm 7 / 8.9 \pm 4$ & $12.2 \pm 6 / 10.4 \pm 6$ & $0.4 /<0.001$ \\
\hline $\begin{array}{l}\text { Neutrophil count on admission/ } \\
\text { discharge (normal } 2.0-7.7 \times 10^{9} / \text { ) }\end{array}$ & $10.4 \pm 6 / 6.6 \pm 4$ & $10.5 \pm 6 / 6.3 \pm 3$ & $10.1 \pm 6 / 8.0 \pm 6$ & $0.5 /<0.001$ \\
\hline $\begin{array}{l}\text { Platelet count on admission/ } \\
\left.\text { discharge (normal } 140-450 \times 10^{9} / 1\right)\end{array}$ & $229 \pm 93 / 287 \pm 122$ & $230 \pm 93 / 300 \pm 123$ & $226 \pm 93 / 221 \pm 86$ & $0.6 /<0.001$ \\
\hline $\begin{array}{l}\text { MPV on admission/discharge } \\
\text { (normal } 7.3-11.5 \mathrm{fL} \text { ) }\end{array}$ & $8.64 \pm 1.2 / 8.48 \pm 1.2$ & $8.67 \pm 1.3 / 8.29 \pm 1.1$ & $8.44 \pm 0.9 / 9.46 \pm 1.1$ & $0.03 /<0.001$ \\
\hline MPV on admission $\leq 8.5 />8.5 \mathrm{fL}$ & $51.7 \% / 48.3 \%$ & $50.7 \% / 49.3 \%$ & $57 \% / 43 \%$ & 0.1 \\
\hline MPV on discharge $\leq 8.5 />8.5 \mathrm{fL}$ & $57 \% / 43 \%$ & $64.3 \% / 35.7 \%$ & $19 \% / 81 \%$ & $<0.001$ \\
\hline $\begin{array}{l}\text { Duration between MPV } \\
\text { measurements (days) }\end{array}$ & $7.4 \pm 9$ & $7.2 \pm 8$ & $8.3 \pm 10$ & 0.2 \\
\hline \multicolumn{5}{|l|}{ In-hospital outcomes } \\
\hline Transfer to intensive care unit & $3.8 \%$ & $3.7 \%$ & $4.4 \%$ & 0.6 \\
\hline Mechanical ventilation & $9.2 \%$ & $6.8 \%$ & $21.5 \%$ & $<0.001$ \\
\hline Duration of hospital stay (days) & $8.1 \pm 9$ & $7.9 \pm 8$ & $9.0 \pm 10$ & 0.1 \\
\hline Death & $6.3 \%$ & $3.3 \%$ & $21.5 \%$ & $<0.001$ \\
\hline
\end{tabular}

Data are presented as means \pm SD or percentages of presented cases. MPV mean platelet volume; $\triangle \mathrm{MPV}$ : MPV on discharge minus MPV on admission; CURB-65: assigning 1 point each for confusion, blood urea nitrogen $>19 \mathrm{~g} / \mathrm{dll}$, respiratory rate $\geq 30 \mathrm{breaths} / \mathrm{min}$, low blood pressure and age $\geq 65$ years; $W B C$ white blood cell. Bold entries in the table indicate a $p$-value of $\leq 0.05$ 
investigation included a larger sample size and hospitalized patients only. Moreover, in addition to admission, we determined MPV values at discharge and MPV changes during hospitalization. Finally, we evaluated in-hospital and long-term outcomes. Using a similar cut-off for MPV values as in the study of Golcuk et al. [20], we did not find a significant difference in in-hospital and long-term mortality rates between patients with baseline MPV levels below and above the threshold. Interestingly, MPV values above the cut-off at discharge were associated with an increased risk of mechanical ventilation and death during the current hospitalization, and shortened survival following discharge. However, in multivariate analysis, MPV at discharge was not one of the variables most significantly associated with poor outcomes. Thus, in our patient population, MPV determined once at any point of time probably appears as a marker of the severity of pneumonia and comorbidities, rather than as an independent predictor of prognosis.

A strength of this study is the evaluation in detail of demographic, clinical, laboratory and radiographic characteristics associated with MPV changes during hospitalization for CAP. Information regarding the association of clinical characteristics with dynamic MPV changes is scarce. In three available studies of patients with coronary artery disease and sepsis, rising MPV was associated with increasing age, renal failure and peripheral artery disease $[9,14,15]$. We also observed that rising MPV is associated with age and renal dysfunction. Moreover, our patients with a rise in MPV were more likely to present with cerebrovascular disorder and severe pneumonia than patients with no rise in MPV. The main potential mechanism for rising MPV in our patient population is severe inflammation caused by pneumonia. In severe infection, increased release of thrombopoietin and various inflammatory cytokines, such as interleukin-1, -3 and -6 and tumor necrosis factor- $\alpha$, result in increased thrombopoiesis and enhanced expression of younger large platelets into the blood circulation $[2,4,8,10]$. On the other hand, rising MPV may be attributed to increased thrombocyte consumption in the peripheral tissue and spleen, induced by severe inflammatory status $[4$, 8 , 10]. Indeed, in our patient population, a rise in MPV was associated with higher pneumonia severity scores, higher levels of leukocytes and neutrophils at

Table 2 Variables that were most significantly associated with in-hospital outcomes in the entire study population (stepwise logistic regression analysis)

\begin{tabular}{|c|c|c|c|}
\hline In-hospital outcomes & $p$-value & Relative risk & 95\% confidence interval \\
\hline \multicolumn{4}{|c|}{ Transfer to intensive care unit (AUC $=0.73$ ) } \\
\hline $\mathrm{Age}^{\mathrm{a}}$ & 0.011 & 0.587 & $0.46-0.75$ \\
\hline Pneumonia Severity Index score ${ }^{b}$ & $<0.001$ & 2.75 & $1.63-4.65$ \\
\hline Coronary artery disease & 0.027 & 3.00 & $1.32-6.82$ \\
\hline Cerebrovascular disease & 0.011 & 0.169 & $0.38-0.76$ \\
\hline Hypoalbuminemia on admission & 0.020 & 2.56 & $1.26-5.21$ \\
\hline \multicolumn{4}{|l|}{ Mechanical ventilation $(A \cup C=0.86)$} \\
\hline Pneumonia Severity Index score ${ }^{b}$ & $<0.001$ & 4.27 & $2.98-6.11$ \\
\hline$\Delta M P V \geq 0.6 \mathrm{fL}$ & $<0.001$ & 2.62 & $1.54-4.45$ \\
\hline Chronic lung disease & 0.04 & 1.76 & $1.07-2.90$ \\
\hline Cerebrovascular disease & 0.037 & 1.70 & $1.00-2.56$ \\
\hline \multicolumn{4}{|c|}{ Prolonged ( $>7$ days) hospital stay $(\mathrm{AUC}=0.72$ ) } \\
\hline Pneumonia Severity Index score ${ }^{b}$ & $<0.001$ & 2.28 & $1.89-2.77$ \\
\hline Chronic lung disease & 0.004 & 1.61 & $1.18-2.21$ \\
\hline Hypoalbuminemia on admission & 0.01 & 1.44 & $1.06-1.95$ \\
\hline Female sex & 0.015 & 1.37 & $1.02-1.85$ \\
\hline \multicolumn{4}{|l|}{ 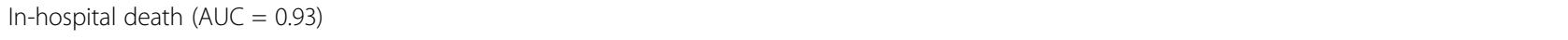 } \\
\hline$\Delta M P V \geq 0.6 \mathrm{fL}$ & $<0.001$ & 6.79 & $3.48-13.20$ \\
\hline Cerebrovascular disease & $<0.001$ & 3.96 & $2.03-7.73$ \\
\hline Pneumonia Severity Index score ${ }^{b}$ & $<0.001$ & 3.90 & $2.29-6.64$ \\
\hline $\mathrm{Age}^{\mathrm{a}}$ & 0.004 & 1.73 & $1.17-2.55$ \\
\hline
\end{tabular}

AUC: the area under the curve of the receiver operating characteristic plots; $\triangle \mathrm{MPV}$ : MPV (mean platelet volume) on discharge minus MPV on admission. ${ }^{\mathrm{a}}$ For each 10 year increment. ${ }^{b}$ For each 50 points increment 


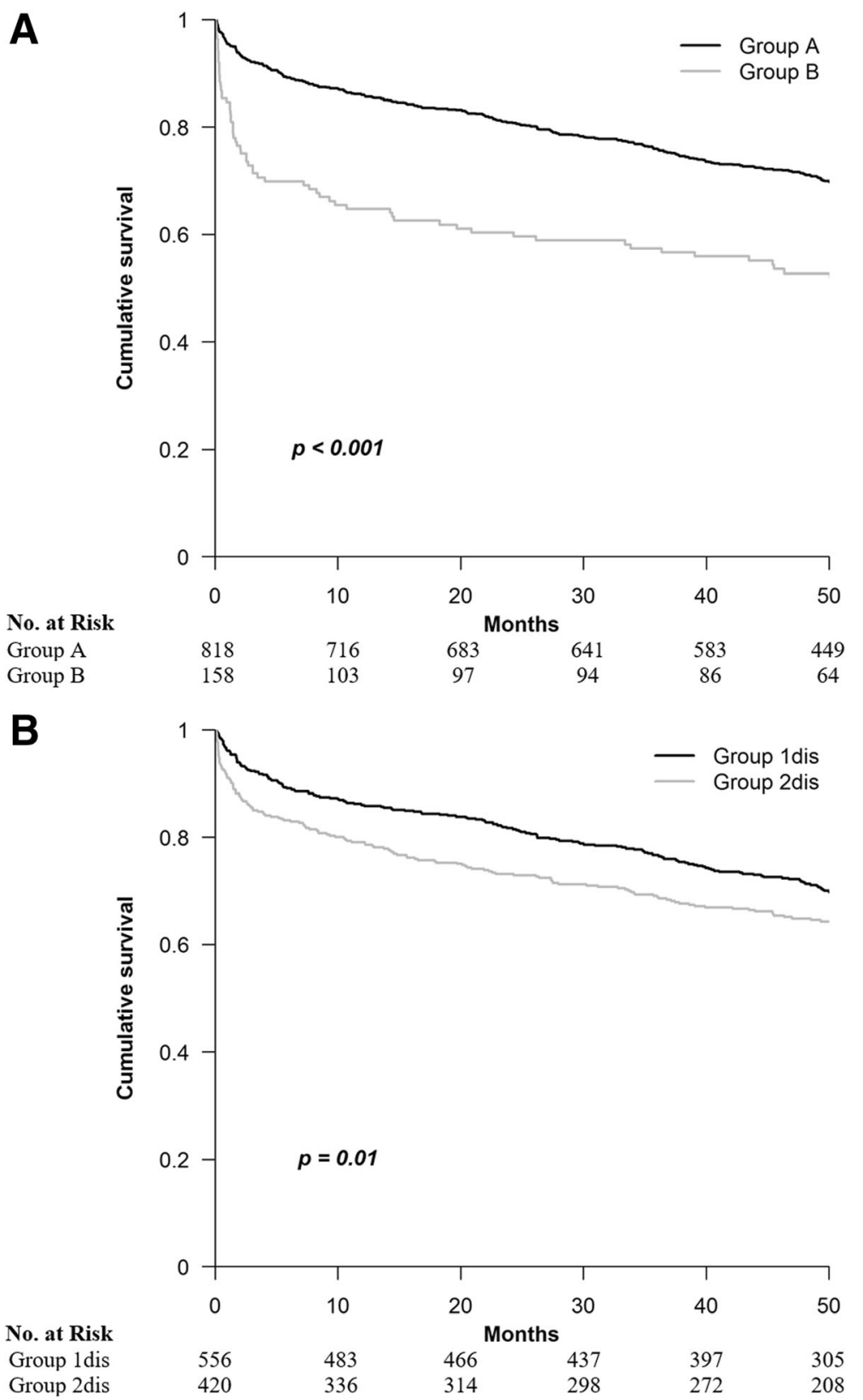

Fig. 1 The Kaplan-Meier estimates of survival for the various study groups. a - Association between $\triangle M P V$ and survival. Group A - no rising $\mathrm{MPV}(\triangle \mathrm{MPV}<0.6 \mathrm{fL})$. Group B - rising MPV $(\triangle \mathrm{MPV} \geq 0.6 \mathrm{fL})$. $\mathbf{b}-$ Association between MPV on discharge and survival. Group $1 \mathrm{dis}-\mathrm{MPV} \leq 8.5 \mathrm{fL}$. Group 2 dis - MPV > $8.5 \mathrm{fL}$ on discharge. MPV: mean platelet volume; $\triangle \mathrm{MPV}$ : MPV on discharge minus MPV on admission

discharge, and lower platelet counts on discharge. Another possible contributing factor to a rise in MPV in our patients is renal dysfunction which is known to be associated with increasing MPV [14, 25]. Hypoxemia, which may cause increased platelet consumption and bone marrow stimulation is an additional explanation for a rise in MPV [11].

The prognostic significance of time-dependent MPV changes has not been reported in patients with pneumonia. Our most interesting finding is the demonstration that a rise in MPV during hospitalization for CAP, even to values within the normal range, predicted treatment with mechanical ventilation and hospital death, as well as increased mortality following discharge from the hospital. Moreover, rising MPV was the most powerful predictor for in-hospital death. A rise in MPV less strongly predicted increased long-term mortality than did advanced age, cerebrovascular disease and higher PSI and CURB-65 scores, but it remained one of variables that was most significantly associated with shortened survival. In contrast to other powerful predictors of 
Table 3 Variables that were most significantly associated with low survival in the entire cohort (Cox proportional-hazards model)

\begin{tabular}{|c|c|c|c|}
\hline Variable & $p$-value & Relative risk & 95\% confidence interval \\
\hline \multicolumn{4}{|c|}{ Model with Pneumonia Severity Index score } \\
\hline $\mathrm{Age}^{\mathrm{a}}$ & $<0.001$ & 1.60 & $1.44-1.79$ \\
\hline Pneumonia Severity Index score ${ }^{b}$ & $<0.001$ & 1.85 & $1.53-2.22$ \\
\hline Cerebrovascular disease & $<0.001$ & 2.15 & $1.68-2.74$ \\
\hline$\Delta M P V \geq 0.6 \mathrm{fL}$ & 0.001 & 1.26 & $1.11-1.43$ \\
\hline History of malignancy & 0.001 & 1.78 & $1.31-2.44$ \\
\hline Heart failure & 0.003 & 1.46 & $1.13-1.88$ \\
\hline Hypoalbuminemia on admission & 0.009 & 1.43 & $1.14-1.78$ \\
\hline Chronic lung disease & 0.015 & 1.32 & $1.06-1.64$ \\
\hline \multicolumn{4}{|l|}{ Model with CURB-65 class } \\
\hline $\mathrm{Age}^{\mathrm{a}}$ & $<0.001$ & 1.75 & $1.58-1.95$ \\
\hline Cerebrovascular disease & $<0.001$ & 2.37 & $1.86-3.02$ \\
\hline Heart failure & $<0.001$ & 1.77 & $1.39-2.25$ \\
\hline CURB- $65^{c}$ & $<0.001$ & 1.30 & $1.14-1.49$ \\
\hline History of malignancy & $<0.001$ & 1.86 & $1.36-2.55$ \\
\hline$\Delta M P V \geq 0.6 \mathrm{fL}$ & 0.001 & 1.23 & $1.08-1.41$ \\
\hline Hypoalbuminemia on admission & 0.003 & 1.44 & $1.16-1.80$ \\
\hline Chronic lung disease & 0.006 & 1.36 & $1.09-1.69$ \\
\hline Female sex & 0.019 & 0.77 & $0.62-0.96$ \\
\hline
\end{tabular}

SMPV: MPV (mean platelet volume) on discharge minus MPV on admission; CURB-65: assigning 1 point each for confusion, blood urea nitrogen > 19 g/dl, respiratory rate $\geq 30$ breaths/min, low blood pressure and age $\geq 65$ years. ${ }^{a}$ For each 10 year increment. ${ }^{b}$ For each 50 points increment. ${ }^{c}$ For each 1 point increment

poor prognosis that were determined on hospital admission, the $\triangle \mathrm{MPV}$ reflected dynamic MPV changes throughout hospitalization. Thus, we suggest that repeated assessment of a simple routine parameter such as MPV during hospitalization may provide additional prognostic information and improve risk stratification for CAP patients. Our findings are in concordance with the results of a number of studies in various patient populations and with various designs [8-15]. Firstly, a rise in MPV in the first $24 \mathrm{~h}$ after admission to the ICU [12] and during hospitalization in the ICU $[8,11]$ was associated with higher hospital mortality. Secondly, MPV elevation during hospitalization for sepsis [14] and within 3 weeks after bacteremia [10] strongly predicted 30-day mortality. Finally, rising MPV within $24 \mathrm{~h}$ after admission for acute myocardial infarction [15], during hospitalization in an internal medicine ward [13] and 3 years following percutaneous coronary intervention [9] was associated with increased long-term mortality.

The underlying pathophysiological mechanisms for a relationship of rising MPV with poor prognosis are not fully understood. The main potential explanation is increased platelet activation [1-4]. Larger thrombocytes are known to be functionally, metabolically and enzymatically more active than smaller ones [1-4]. The greater activation of enlarged platelets results in increased release of procoagulant substances such as thromboxane A2, $\beta$-thromboglobulin and surface proteins [1-4]. Consequent hyperaggregability of platelets, extended vasoconstriction and endothelial dysfunction may contribute to an increased short-term risk of cardiovascular thrombosis and death in patients with rising MPV [3, 4]. Moreover, large thrombocytes more actively secrete from their granules cytokines, enzymes, oxidants and other proteins, which may decrease immune function of platelets and other circulating cells, and increase detrimental processes of oxidation and apoptosis $[1,2,11]$. We suggest that the abovementioned negative effects of persistent increased activation of enlarged platelets following acute infection is a possible underlying mechanism of increased long-term mortality in our patients.

The present investigation has a few limitations. First, this is a single-center study. Furthermore, the retrospective design precludes determining a definitive relationship between MPV changes and outcomes. Finally, possible selection bias and missing data, which is typical of observational research, may have impacted the results.

\section{Conclusions}

Rising MPV during hospitalization for CAP is associated with more severe clinical and laboratory characteristics than no rise in MPV. Rising MPV is a powerful predictor of in-hospital and long-term mortality. We suggest that repeated MPV determinations throughout hospitalization may improve risk stratification for CAP patients. 


\section{Abbreviations}

ANOVA: Analysis of variance; AUC: Area under curve; BMDP: Biomedical package; CAP: Community-acquired pneumonia; CURB-65: assigning 1 point each for Confusion, blood Urea nitrogen $>19 \mathrm{~g} / \mathrm{dl}$, Respiratory rate $\geq 30$ breaths/min, low Blood pressure and age $\geq 65$ years; ICU: Intensive care unit; MPV: Mean platelet volume; PSI: Pneumonia severity index; WBC: White blood cell

\section{Acknowledgements}

Not applicable

\section{Funding}

Not applicable

\section{Availability of data and materials}

The datasets analyzed during the current study are available from the corresponding author on reasonable request.

\section{Authors' contributions}

Study concept and design: OG, NC, SI. Acquisition, analysis and interpretation of data: OG, IT, DB, DA-S, MS, IB, LF, NC, SI. All authors contributed to the first draft, critically reviewed and revised subsequent drafts. All authors read and approved the final manuscript.

\section{Ethics approval and consent to participate}

The study was approved by the institutional Ethics Committee of the Assaf Harofeh Medical Center (approval number 0195-16-ASF). All patient data were anonymous, so informed consent for participation was not required.

\section{Consent for publication}

Not applicable

\section{Competing interests}

The authors declare that they have no competing interests.

\section{Publisher's Note}

Springer Nature remains neutral with regard to jurisdictional claims in published maps and institutional affiliations.

\section{Author details}

'Department of Internal Medicine "F", Assaf Harofeh Medical Center, 70300 Zerifin, Israel. ${ }^{2}$ Nephrology Division, Assaf Harofeh Medical Center, Zerifin, Israel. ${ }^{3}$ Sackler Faculty of Medicine, Tel Aviv University, Ramat Aviv, Tel Aviv, Israel.

Received: 28 May 2017 Accepted: 26 October 2017

Published online: 30 October 2017

\section{References}

1. Kamath S, Blann AD, Lip GY. Platelet activation: assessment and quantification. Eur Heart J. 2001;22:1561-71.

2. Ware J, Corken A, Khetpal R. Platelet function beyond hemostasis and thrombosis. Curr Opin Hematol. 2013;20:451-6.

3. Chu SG, Becker RC, Berger PB, et al. Mean platelet volume as a predictor of cardiovascular risk: a systematic review and meta-analysis. J Thromb Haemost. 2010:8:148-56.

4. Noris P, Melazzini F, Balduini CL. New roles for mean platelet volume measurement in the clinical practice? Platelets. 2016:27:607-12.

5. Arévalo-Lorido JC, Carretero-Gómez J, Álvarez-Oliva A, Gutiérrez-Montaño C, Fernández-Recio JM, Najarro-Diez F. Mean platelet volume in acute phase of ischemic stroke, as predictor of mortality and functional outcome after 1 year. J Stroke Cerebrovasc Dis. 2013;22:297-303.

6. Wasilewski J, Desperak P, Hawranek M, et al. Prognostic implications of mean platelet volume on short and long-term outcomes among patients with non-ST-segment elevation myocardial infarction treated with percutaneous coronary intervention: a single-center large observational study. Platelets. 2016:27:452-8.

7. Pyo J-S, Sohn JH, Kang G. Diagnostic and prognostic roles of the mean platelet volume in malignant tumors: a systemic review and meta-analysis. Platelets. 2016;27:722-8.
8. Becchi C, Al Malyan M, Fabbri LP, Marsili M, Boddi V, Boncinelli S. Mean platelet volume trend in sepsis: is it a useful parameter? Minerva Anestesiol. 2006;72:749-56.

9. Shah B, Oberweis B, Tummala $L$, et al. Mean platelet volume and long-term mortality in patients undergoing percutaneous coronary intervention. Am J Cardiol. 2013;111:185-9.

10. Kitazawa T, Yoshino Y, Tatsuno K, Ota Y, Yotsuyanagi $H$. Changes in the mean platelet volume levels after bloodstream infection have prognostic value. Intern Med. 2013:52:1487-93.

11. Sezgi C, Taylan M, Kaya $H$, et al. Alterations in platelet count and mean platelet volume as predictors of patient outcome in the respiratory intensive care unit. Clin Respir J. 2015;9:403-8

12. Zampieri FG, Ranzani OT, Sabatoski $\mathrm{V}$, et al. An increase in mean platelet volume after admission is associated with higher mortality in critically ill patients. Ann Intensive Care. 2014:4:20.

13. Shteinshnaider M, Barchel D, Almoznino-Sarafian D, et al. Clinical characteristics and prognostic significance of changes in platelet count in an internal medicine ward. Eur J Intern Med. 2014;25:646-51.

14. Kim CH, Kim SJ, Lee MJ, et al. An increase in mean platelet volume from baseline is associated with mortality in patients with severe sepsis or septic shock. PLoS One. 2015;10:e0119437.

15. Kırış T, Yazici S, Günaydin ZY, et al. The prognostic impact of in-hospital change in mean platelet volume in patients with non-ST-segment elevation myocardial infarction. Angiology. 2016:67:690-6.

16. Musher DM, Thorner AR. Community-acquired pneumonia. N Engl J Med. 2014:371:1619-28.

17. Jain $\mathrm{S}$, Self WH, Wunderink RG, et al. Community-acquired pneumonia requiring hospitalization among U.S. adults. N Engl J Med. 2015;373:415-27.

18. Eurich DT, Marrie TJ, Minhas-Sandhu JK, et al. Ten-year mortality after community-acquired pneumonia: a prospective cohort. Am J Resp Crit Care Med. 2015:192:597-604

19. Karadag-Oncel E, Ozsurekci Y, Kara A, Karahan S, Cengiz AB, Ceyhan M. The value of mean platelet volume in the determination of community acquired pneumonia in children. Ital J Pediatr. 2013;39:16

20. Golcuk Y, Golcuk B, Bilge A, Irik M, Dikmen O. Combination of mean platelet volume and the CURB-65 score better predicts 28-day mortality in patients with community-acquired pneumonia. Am J Emerg Med. 2015:33:648-52.

21. Levey AS, Coresh J, Greene T, et al. Chronic kidney disease epidemiology collaboration. Using standardized serum creatinine values in the modification of diet in renal disease study equation for estimating glomerular filtration rate. Ann Intern Med. 2006;145:247-54.

22. Fine MJ, Auble TE, Yealy DM, et al. A prediction rule to identify lowrisk patients with community-acquired pneumonia. N Engl J Med. 1997; $336: 243-50$

23. Lim WS, van der Eerden MM, Laing R, et al. Defining community acquired pneumonia severity on presentation to hospital: an international derivation and validation study. Thorax. 2003;58:377-82.

24. Dixon WJ, editor. BMDP statistical software. Los-Angeles: University of California Press; 1993.

25. Ju HY, Kim JK, Hur SM, et al. Could mean platelet volume be a promising biomarker of progression of chronic kidney disease? Platelets. 2015:26:143-7.

\section{Submit your next manuscript to BioMed Central and we will help you at every step:}

- We accept pre-submission inquiries

- Our selector tool helps you to find the most relevant journal

- We provide round the clock customer support

- Convenient online submission

- Thorough peer review

- Inclusion in PubMed and all major indexing services

- Maximum visibility for your research

Submit your manuscript at www.biomedcentral.com/submit
BioMed Central 